\title{
COMPARATIVE ANALYSIS OF THE VIEWS OF SAINT PETERSBURG TEACHERS ON THE ROLE AND ESSENTIAL CHARACTERISTICS OF PEDAGOGICAL DIAGNOSTICS
}

(C) 2016

\author{
I.Yu. Gutnik, candidate of pedagogical sciences, associate professor of Chair of Pedagogy \\ Herzen State Pedagogical University of Russia, Saint Petersburg (Russia)
}

\begin{abstract}
The article presents a comparative analysis of the perceptions of St. Petersburg teachers from a representative sampling and analysis of opinions of teachers one of the schools of St. Petersburg that has a lot of experience in pedagogical diagnostics aimed at the students' self-determination. As a result of the comparative analysis it was ascertained that the teachers are aware of the necessity of pedagogical diagnostics in modern educational process. Our research confirmed the teachers' awareness of the importance of daily, close to the intuitive knowledge of their students and that the existing experience of student support based on educational diagnostics, makes it necessary for the teacher to know the students' problems and difficulties. Teachers lack knowledge and skills as far as the use of different sources for information about the student is concerned. Teachers do not quite understand the importance of applying qualitative and authentic methods of diagnosis, as well as the importance of taking into account the opinions of the colleagues and need to interact with them, the significance of collectively, jointly developing a mechanism and diagnostic support for all school staff. It is shown that the training in the theory and practice of pedagogical diagnosis allows teachers to eliminate many problems of pedagogical diagnostics, namely, its being labor- and time-consuming.

Keywords: pedagogical diagnostics, pedagogical support, support, methods of pedagogical diagnostics, pedagogical rational and intuitive diagnosis, observation, questionnaire, interview, portfolio, methods of diagnosis, student selfdetermination, informal tests.
\end{abstract}

\section{УДК 372.8}

\section{СОВЕРШЕНСТВОВАНИЕ ФОРМИРОВАНИЯ ЭКОНОМЕТРИЧЕСКИХ ЗНАНИЙ ПРИ ОБУЧЕНИИ БАКАЛАВРОВ - ПЕДАГОГОВ ЭКОНОМИЧЕСКОГО ПРОФИЛЯ}

(C) 2016

Ю.В. Зелепухин, кандидат технических наук, доцент, заведующий кафедрой экономического образования

О.Ю. Цыбина, старший преподаватель кафедры экономического образования

Самарский государственный соииально-педагогический университет, Самара (Россия)

Аннотащия. Концепция модернизации российского образования ставит вопрос о необходимости введения профильного обучения для совершенствования и развития школьной системы образования. Актуально то, что для реализации идей усовершенствования образования первоочередной задачей является наличие высококвалифированных учителей для работы в профильных классах. Одним из самых сложных является обучение студентов для работы в классах социально-экономического профиля. Будущие учителя, обучающиеся по профилю «Экономика», должны использовать экономико-математические и эконометрические методы при решении социальноэкономических вопросов, знать достижения мировой экономической мысли, обладать общей экономикоматематической культурой. Для достижения этих целей в вузах преподаётся эконометрика. Являясь междисциплинарной наукой, она базируется на математических и экономических знаниях. За последние 40 лет произошло стремительное развитие эконометрики как научной дисциплины. Как свидетельство международного признания и значимости выступило награждение нобелевскими премиями в области экономики за выдающиеся исследования в области эконометрики таким учёным, как Рагнар Фриш и Ян Тинберген, Джеймс Хекман и Дэниел Макфадден. Стоит отметить, что всё больше эконометрические методы применяются в различных публикациях и исследованиях. В эконометрику глубоко проникают новейшие информационные технологии и математические методы. Изучение эконометрики студентами-педагогами экономического профиля положительно влияет на познание мира и усвоение различных знаний, так как математический язык считается универсальным и тот, кто умеет им пользоваться, успешно сможет применить свои знания в различных областях науки и производства. Статья посвящена вопросам совершенствования формирования эконометрических знаний при обучении бакалавров-педагогов экономического профиля.

Ключевые слова: концепция модернизации российского образования, эконометрические знания, экономическое мышление, экономико-математические и эконометрические методы, бакалавры-педагоги экономического профиля, учебный план, основная образовательная программа, федеральный государственный образовательный стандарт высшего профессионального образования, направление подготовки «Педагогическое образование», профессиональные компетенции, активные методы обучения, компетентностный подход к образованию.

Результатом присоединения России к Болонскому процессу стало то, что многие общеуниверситетские дисциплины подготовки студентов стали преподавать студентам педагогических вузов. Популярным стало направление эконометрическое моделирование, объединяющее математические методы, которые основываются на экономической теории, экономической ста- тистике, математико-статистическом инструментарии, с целью придания конкретных количественных выражений общим закономерностям $[1,2,3,4,5,6,7]$.

Основной отличительной особенностью Болонского процесса можно назвать процесс трансформации знаний, умений и навыков в некие компетенции, которые буду необходимы выпускнику впоследствии в профес- 
сиональной деятельности $[8,9,10,11]$ Эконометрические знания при обучении бакалавров-педагогов экономического профиля способствуют формированию таких компетенций, как:

- общекультурных компетенций: владение культурой мышления, способность к обобщению, анализу, восприятию информации, постановке цели и выбору путей её достижения; способность логически верно, аргументировано и ясно строить устную и письменную речь;

- профессиональных компетенций: способность использовать возможности образовательной среды, в том числе информационной, для обеспечения качества учебно-воспитательного процесса ; способность выбирать инструментальные средства для обработки экономических данных в соответствии с поставленной задачей, проанализировать результаты расчётов и обосновать полученные выводы ; способность на основе описания экономических процессов и явлений строить стандартные теоретические и эконометрические модели, анализировать и содержательно интерпретировать полученные результаты.

Сформированная профессиональная компетентность должна помочь студентам безболезненно адаптироваться к изменениям в современном обществе посредством интеллектуальной восприимчивости, интеллектуальной подвижности, гибкости мышления.

Нами проведен анализ учебного плана бакалавров педагогов экономического профиля СГСПУ в контексте формирования эконометрических знаний и умений.

В учебном плане эконометрика относится к вариативной части профессионального цикла, читается в 6 семестре на 3 курсе. Общая трудоёмкость в часах - 144, причём из них только 42 из них отводится на аудиторную работу (26 на лекции и 16 на практические занятия). 66 часов студент должен работать самостоятельно (рис. 1, 2).

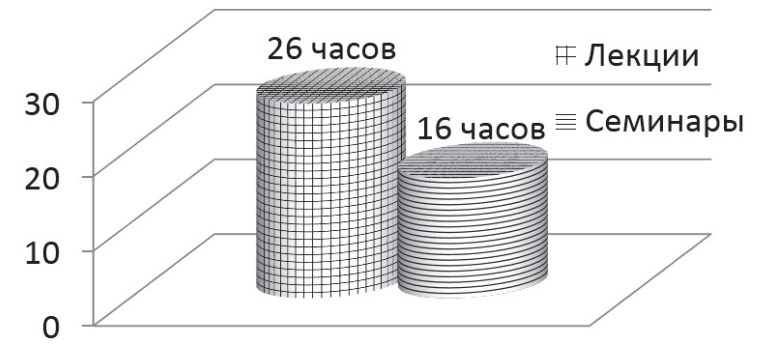

Рисунок 1 - Количество часов, выделяемых на аудиторную работу по дисциплине «Эконометрика»

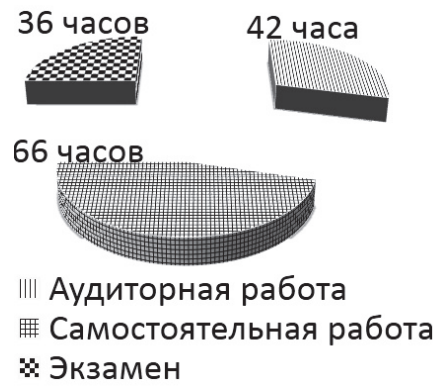

Рисунок 2 - Трудоёмкость дисциплины «Эконометрика»

Изучение эконометрики базируется на математических и экономических знаниях бакалавров-педагогов. При анализе трудоёмкости всех дисциплин, участвующих в формировании эконометрических знаний, мы пришли к выводу, что количество часов, выделяемых на экономические дисциплины значительно больше, чем на математические (рис. 3).

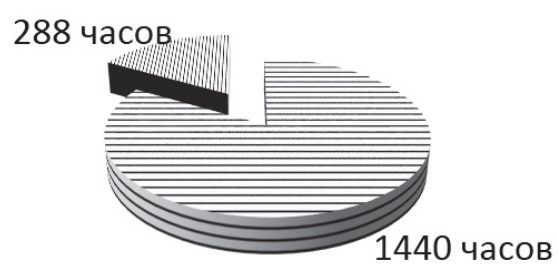

\section{三 Экономические дисциплины}

||| Математические дисциплины

Рисунок 3 - Соотношение экономических и математических дисциплин в учебном плане бакалавров-педагогов экономического профиля в СГСПУ

Математическая подготовка - это база для обучения бакалавров-педагогов экономического профиля профильным дисциплинам, к которым относится и эконометрика. Переход на двухуровневую систему обучения привёл к сокращению часов, отводимых на изучение математики, на 40-50\%. Следствием этого является резкое снижение качества подготовки студентов, так как математические знания являются основой при изучении многих наук, для педагогов-бакалавров экономического профиля все они являются профильными.

Мы считаем, что математическая подготовка бакалавров-педагогов экономического профиля должна проходить в три этапа:

1) Общеразвивающий. Этот этап заключается в обучении студентов базовым математическим знаниям, умениям, навыкам, закладывании основ математической культуры. Важным является предоставить возможность и психологически подготовить студентов использовать математические методы в изучении других учебных предметов. На данном этапе необходимо, чтобы обучающиеся осознавали тесноту связи между математическими и экономическими понятиями. Пример взаимосвязанных понятий: «отношение порядка - отношение предпочтения», «производная функции - производительность труда», «экстремум функции - оптимальный выбор» и т.д.

2) Ориентировочно-профессиональный. На этом этапе студенты приобретают знания о математических моделях в экономике, о математических методах их исследования. Обучающиеся умеют объединять знания различных областей наук и осознают значимость этого умения. Углубляя профессиональные ориентации, студенты применяют математическое моделирование на практике. Процесс приобретения новых знаний и их углубление будет эффективнее, если они связаны с потребностями современной математической и экономической наук.

3) Общепрофессиональный.

В таблице 1 представлены типовые профессиональные задачи, которые решаются с помощью математических методов.

Изучение математики не только даёт студентам нужные знания, но и развивает способности в исследовании и решении задач. Математические знания являются прочным и незаменимым фундаментом в освоении профильных дисциплин бакалаврами-педагогами экономического профиля. Кроме этого, именно с помощью них развивается логическое мышление, аккуратность, усидчивость, концентрация внимания [12, $13,14]$ 
Таблица 1 - типовые профессиональные задачи, которые решаются с помощью математических методов

\begin{tabular}{|l|l|l|}
\hline \multicolumn{1}{|c|}{ Название } & \multicolumn{1}{|c|}{ Цель } & \multicolumn{1}{c|}{ Пример } \\
\hline $\begin{array}{l}\text { Обработка информа- } \\
\text { ции }\end{array}$ & $\begin{array}{l}\text { Выбрать и предоставить в конкретном виде нужную } \\
\text { информацию. }\end{array}$ & $\begin{array}{l}\text { 1) Первичная обработка данных по } \\
\text { определённому признаку. } \\
\text { 2) Классификация. } \\
\text { 3) Описательная статистика. }\end{array}$ \\
\hline $\begin{array}{l}\text { Оценка показателей } \\
\text { экономической дея- } \\
\text { тельности }\end{array}$ & $\begin{array}{l}\text { Вычисление и оценка значений показателей эконо- } \\
\text { мической деятельности. }\end{array}$ & $\begin{array}{l}\text { 1) Задача теории игр. } \\
\text { 2) Задачи финансовой математики. }\end{array}$ \\
\hline $\begin{array}{l}\text { Определение зави- } \\
\text { симости между па- } \\
\text { раметрами экономи- } \\
\text { ческой деятельности }\end{array}$ & $\begin{array}{l}\text { Установить зависимость между параметрами эко- } \\
\text { номической деятельности. }\end{array}$ & $\begin{array}{l}\text { 1) Задача регрессионного анализа. } \\
\text { 2) Задача сравнительной статистики. }\end{array}$ \\
\hline $\begin{array}{l}\text { Прогноз } \\
\text { а) Разработка системы действий для создания объ- } \\
\text { екта, обладающего определёнными свойствами. }\end{array}$ & $\begin{array}{l}\text { 1) Анализ задача теориенных дифференцияль } \\
\text { ных игр }\end{array}$ \\
\hline
\end{tabular}

Как показал анализ учебного плана бакалавров педагогов экономического профиля СГСПУ, курс «Основы математической обработки информации» читается на первом году обучения бакалавров-педагогов и его усвоение является для них сложным. Причина этого в том, что на большой объём информации, которую необходимо изучить, приходится маленький объём аудиторных часов. Это приводит к тому, что курс становится насыщенным на понятия, идеи, методы и большинство студентов не осваивают столько информации. В результате приходится отказываться от изучения многих разделов: векторной алгебры, аналитической геометрии, комплексных чисел и многочленов и т.д.

Среди студентов факультета экономики, управления и сервиса СГСПУ был проведен опрос, целью которого являлся анализ уровень математической подготовки. Исследованию подверглись несколько периодов обучения: школьная подготовка, вступительные испытания и обучение в академии. На каждом из этих периодов уровень математической подготовки был определён количественно (в баллах по пятибалльной системе оценивания) и затем переведён в проценты. Учитывались оценки по математике за среднюю школу (ЕГЭ или аттестат), оценки на экзамене в вузе по математике на первом курсе, статистике на втором и эконометрике на третьем курсе. На 4 курсе опрошенные выставляли баллы, опираясь на результаты самооценки. Анализ полученных данных выявил тенденцию к уменьшению уровня математической подготовки студентов на третьем и четвертом курсе обучения. Период довузовского обучения и обучения на первом и втором курсах характеризуются высоким уровнем математической подготовки. Особенно повышенным математическим потенциалом обладают школьники, поступающие в СГСПУ (рис. 4).

Он сохраняется на 1 и 2 курсах. На третьем курсе математический потенциал снижается до 3,59 и показатель качественной успеваемости до 65\%. Результаты опроса показывают, что на 4 курсе студенты владеют и используют математический аппарат в количестве $25 \%$ (5 человек); частично им пользуются 60\% (12 человек); студентов, которые думают, что совсем не используют математические знания - 15\% (3 человека). Полученные результаты показывают общее снижение математической подготовки студентов, что влияет и на снижение качества подготовки будущих специалистов.

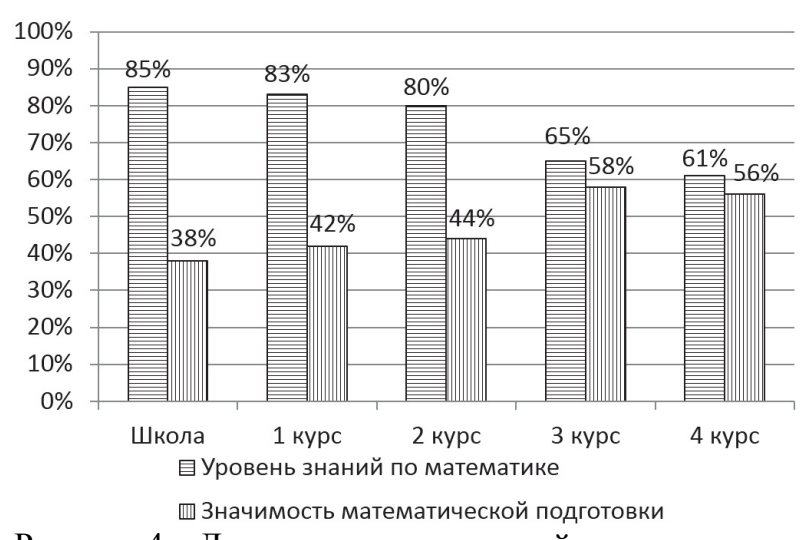

Рисунок 4 - Динамика уровня знаний по математике и уровня значимости математических дисциплин для бакалавров-педагогов экономического профиля

По мнению опрошенных студентов, для них уровень значимости математических знаний с каждым годом увеличивается (от 42\% на первом курсе до 56\% на четвёртом курсе).

Значимость математических знаний для студентов подтверждается и следующими данными - на вопрос анкеты: «Какова доля использования Вами знаний и навыков, полученных по высшей математике на 1 курce, при изучении профильных дисциплин?» были получены такие ответы: в статистике - $60 \%$, в эконометрике - 58\%, в макроэкономике - 45\%, в микроэкономике $46 \%$ (рис. 5 ).

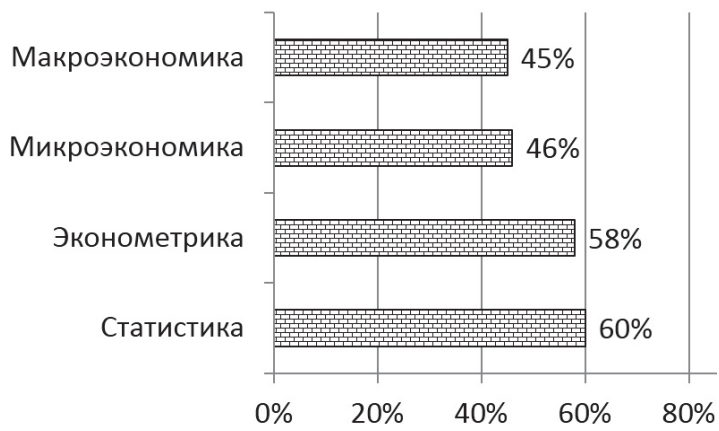

Рисунок 5 - Использование студентами математических знаний при изучении профильных дисциплин

Проведённый анализ показал, что выявленный математический потенциал первокурсников необходимо корректировать, восполнять пробел в их знаниях для дальнейшего успешного процесса обучения. 
Беседы с преподавателями и студентами привели к выводу, что, несмотря на накопленный потенциал методов, форм, средств обучения математике и эконометрике, основой продолжает оставаться традиционная система обучения. В ней преподаватель, в большинстве случаев, информатор и контролёр студентов. При использовании традиционной системы обучения выявляются следующие проблемы:

- студенты пассивны на занятиях;

- у обучающихся низкая мотивация к учёбе;

- нерегулярная самостоятельная работа;

- отсутствует возможность у преподавателя адаптироваться к индивидуальным особенностям каждого студента;

- выборочный контроль за результатами деятельности студентов.

Для совершенствования формирования эконометрических знаний у бакалавров-педагогов экономического профиля можно рекомендовать:

1. Применять адаптивную систему обучения (ACO). Основная цель АСО заключается в том, чтобы развивать личность обучаемого, ориентируясь на его индивидуальные особенности. В учебном процессе изменяется роль студента от объекта к субъекту, он учится самостоятельно ставить цель и достигать её. $[15,16]$

2. Изменение формата аудиторных занятий, насыщение их различными активными формами обучения, что способствуют лучшему усвоению знаний студентами $[17,18,19]$.

На занятиях по эконометрике предлагается использовать: деловую игру. Для студентов это интересная и полезная форма проведения практического занятия. Её использование позволит учащимся быстро понять проблематику изучаемого материала. Игра может проводиться как со всей академической группой, так и с подгруппами, которые получают дифференцированные задания. В процессе такой формы проведения практического занятия вырабатывается важная составляющая профессиональной компетенции - готовность работать в коллективе, происходит социализация студентов. Целью игры является усвоение основных понятий эконометрики, которые применяются в корреляционнорегрессионном анализе и получение студентами практических рекомендаций для выполнения индивидуальных заданий. Темой такой деловой игры может быть: «Отбор факторов, влияющих на цену квартиры». В процессе учащиеся применяют личный опыт, используют различные источники информации. Важно, чтобы они могли проанализировать, сопоставить и аргументировать выбор фактора, определить его влияние на результат. Важным принципом при проведении игры выступает «мозговой штурм», все участники высказывают свои мнения, конструктивно его обсуждают. Результатом являются выбранные факторы и их обоснование.

Полностью уходить от традиционной формы не требуется, но лекции должны содержать большое количество задач прикладного характера, опорных схем, вопросов для самостоятельного изучения. Практические занятия, по нашему мнению, должны измениться по структуре: 20-30 минут преподаватель работает со всей группой, в оставшееся время студенты заняты индивидуальными заданиями. [20]

\section{СПИСОК ЛИТЕРАТУРЫ:}

1. Айвазян С.А., Мхитарян В.С. Прикладная статистика. Основы эконометрики: учебник для вузов: в 2 т.: Т. 1. Теория вероятностей и прикладная статистика. М.: ЮНИТИ-ДАНА, 2001. 656 с.

2. Гладилин А.В. Герасимов А.Н., Громов Е.И. Эконометрика: учебник. Ростов н/Д: Феникс, 2011. 297 с.

3. Дубров А.М., Мхитарян В.С., Трошин Л.И. Многомерные статистические методы: учебник. М.: Финансы и статистика, 2003. 352 с.

4. Орлов А.И. Эконометрика: учеб. для вузов. 3-е изд., перераб. и доп. М.: Издательство «Экзамен», 2004. 576 с.

5. Хаустова О.И. Эконометрика: учебно-методический комплекс. Новосибирск: Изд. НГПУ, 2006. 221 с.

6. Тихомиров Н.П., Дорохина Е.Ю. Эконометрика: учебник. М.: Издательство «Экзамен», 2003. 512 с.

7. Практикум по эконометрике: учеб. пособие / И.И. Елисеева, С.В. Курышева, Н.М. Гордеенко и др.; под ред. И.И. Елисеевой. М.: Финансы и статистика, 2005. 192 с

8. Медведев С.Н. Болонский процесс, Россия и глобализация // Высшее образование в России: Научнопедагогический журнал министерства образования и науки РФ. 2006. № 3. С. 7-11.

9. Зимняя И.А. Компетентность и проблемы ее формирования в системе непрерывного образования (школа - вуз - послевузовское образование) // Актуальные проблемы качества образования и пути их решения: матер. XVI науч.-методич. конф. М.: Исследовательский центр проблем качества подготовки специалистов, 2006. $130 \mathrm{c}$.

10. Дробышева И.В. О содержательном компоненте компетентностно-ориентированного обучения математике студентов вузов // Современное образование: научные подходы, опыт, проблемы, перспективы: материалы VIII Bсерос. науч.-практ. конф. с междунар. участием «Артемовские чтения». Пенза, 2012. Т. 1. С. 31-35.

11. Якиманская И.С. Технология личностно-ориентированного образования / отв. ред. А. Ушакова. М.: Сентябрь, 2000. 176 с.

12. Ливандовская А.Д. Экономика и математика: их взаимодействие // Вестник Тихоокеанского государственного экономического университета. 2008. №4. C. $90-98$.

13. Хабибуллина Г.З. Совершенствование процесса математической подготовки профессионально компетентных учителей // Электронное образование в России: опыт, проблемы, перспективы: Материалы 1-й Всероссийской научно-практической Интернет-конференции. Казань: ТГГПУ, 2011. С. 52-57.

14. Галимянов А.Ф., Исмагилова К.К. Развитие математической культуры студентов, обучающихся на гуманитарных факультетах в вузе // Образовательные технологии и общество (Educational Technology \& Society): Международный электронный журнал. 2011. № 1. C. 380-390.

15. Анисова Т.Л. Адаптивная система обучения математике как средство формирования математических компетенций учащихся вузов и оценки степени их достижения // Фундаментальные исследования. 2012. № 3 (ч. 2). С. 265-268.

16. Анисова Т.Л. Организация практических занятий по математике с использованием адаптивной системы обучения // Перспективы науки. 2011. № 7(21). С. 19-22. 
17. Мединцева И.П. Использование MS EXCEL при обучении студентов эконометрике // Научный вестник Волгоградской академии государственной службы. Серия: Экономика. 2011. Т. 2. № 6. С. 93-96.

18. Селевко Г.К. Проблемное обучение // Школьные технологии. 2006. №2. С. 61-65.
19. Хуторской А.В. Практикум по дидактике и современным методикам обучения. СПб.: Питер, 2004. $541 \mathrm{c}$.

20. Плотникова О., Суханова В. Самостоятельная работа студентов: деятельный аспект // Высшее образование в России. 2005. № 1.

\title{
IMPROVEMENTS IN THE FORMATION OF ECONOMETRIC KNOWLEDGE AT TRAINING OF BACHELORS - TEACHERS OF ECONOMIC PROFILE
}

(C) 2016

\author{
Yu.V. Zelepukhin, candidate of technical sciences, head of the Chair of Economical Education \\ O.Yu. Tsybina, senior lecturer of the Chair of Economical Education \\ Samara State University of Social Sciences and Education, Samara (Russia)
}

\begin{abstract}
The concept of modernization of Russian education raises the question about necessity of introduction of profile training to improve and develop the school system of education. It is important that the implementation of ideas to improve education a priority is the presence of expert teachers to work in specialized classes. One of the most difficult is to educate students to work in classrooms socio-economic profile. Future teachers enrolled in the profile "Economics", must use economic, mathematical and econometric methods in solving socio-economic issues, to know the achievements of world economic thought, have a General mathematical culture. To achieve these goals in higher education is taught econometrics. It is an interdisciplinary science, it is based on mathematical and economic knowledge. Over the past 40 years there has been a rapid development of econometrics as a scientific discipline. As evidence of international recognition and importance was the awarding of the Nobel prize in Economics for outstanding research in the field of econometrics scholars such as Ragnar Frisch and Jan Tinbergen, James Heckman and Daniel McFadden. It should be noted that all econometric methods are used more in different publications and studies. To econometrics deeply penetrate the latest information technologies and mathematical methods. Econometrics students, teachers of economic profile has a positive effect on the cognition of the world and the absorption of various knowledge, since the mathematical language is universal and the one who knows how to use it successfully will be able to apply their knowledge in various fields of science and industry. The article is devoted to the improvement of the formation of econometric knowledge at training of bachelorsteachers of economic profile.

Keywords: the concept of modernization of Russian education, economic knowledge, economic thinking, economicmathematical and econometric methods, bachelors-teachers of economic profile, curriculum, basic educational program, Federal state educational standard of higher professional education, training direction «Pedagogical education», professional competences, active learning methods, competence approach to education.
\end{abstract}

\section{МОДЕЛЬ ОХРАНЫ ТРУДА И ЗДОРОВЬЯ СТУДЕНТОВ СПЕЦИАЛЬНОЙ МЕДИЦИНСКОЙ ГРУППЫ В УСЛОВИЯХ ВУЗА}

(C) 2016

Г.М. Ильмушкин, доктор педагогических наук, профессор кафедры высшей математики

O.B. Пархаева, заведующий кафедрой физической культуры и спорта, аспирант

Ю.Е. Судакова, кандидат педагогических наук, доцент кафедры физической культуры и спорта Димитровградский инженерно-технологический институт -

филиал Национального исследовательского ядерного университета «МИФИ», Димитровград (Россия)

Аннотация. В настоящей работе представлен обзор состояния здоровья студенческой молодежи на современном этапе развития образования в РФ, обоснованы факторы, обуславливающие прогресс ряда устойчивых заболеваний, связанных с условиями умственного труда в ВУЗе. На основе изучения имеющихся фактов и путем анализа медицинской и учебной документации Димитровградского инженерно-технологического института-филиала Национального исследовательского ядерного университета «МИФИ» (ДИТИ НИЯУ МИФИ) представлена динамика численности студентов, отнесенных по состоянию здоровья к специальной медицинской группе (СМГ), а также структура заболеваемости по нозологическим признакам. Данный контингент студентов нуждается в особой организации занятий по физической культуре. В этой связи предложено оптимальное структурирование содержания образования по физическому воспитанию студентов СМГ с учетом их физического состояния здоровья, психоэмоциональных характеристик, мотивационно-ценностного отношения к физическому самосовершенствованию, а также широкого внедрения компетентностного подхода в образовательный процесс по физической культуре. При этом физическое воспитание студентов нами рассматривается в контексте охраны труда и здоровья. Тем самым предложена авторская модель охраны труда и здоровья студентов СМГ. В разработанной модели существенное внимание обращается на совершенствование физического воспитания студентов путем внедрения в учебный процесс инновационных средств педагогической коммуникации.

Ключевые слова: учебная деятельность, физическая культура, здоровье, охрана труда, специальная медицинская группа, ценностное отношение, компетентностный подход. 